\title{
Perinatal, sociodemographic and lifestyle correlates of increased total and visceral fat mass levels in schoolchildren in Greece: the Healthy Growth Study
}

\author{
George Moschonis ${ }^{1,2}$, Adriana C Kaliora ${ }^{1}, K_{\text {Kalliopi Karatzi }}{ }^{1}$, Aggelos Michaletos ${ }^{1}$, \\ Christina-Paulina Lambrinou', Alexandra K Karachaliou ', George P Chrousos ${ }^{3}$, \\ Christos Lionis ${ }^{4}$ and Yannis Manios ${ }^{1, *}$ on behalf of the Healthy Growth Study Group \\ 'Department of Nutrition and Dietetics, School of Health Science and Education, Harokopio University of Athens, \\ 70 El Venizelou Avenue, 17671 Kallithea, Athens, Greece: ${ }^{2}$ EnviNHealth S.A., Athens, Greece: ${ }^{3}$ First Department of \\ Pediatrics, Athens University Medical School, Aghia Sophia Children's Hospital, Athens, Greece: ${ }^{4}$ Clinic of Social \\ and Family Medicine, School of Medicine, University of Crete, Heraklion, Crete, Greece
}

Submitted 9 February 2016: Final revision received 28 July 2016: Accepted 15 August 2016: First published online 8 November 2016

\begin{abstract}
Objective: To identify possibly independent associations of perinatal, sociodemographic and lifestyle factors with childhood total and visceral body fat.

Design: A representative sample of 2655 schoolchildren (9-13 years) participated in the Healthy Growth Study, a cross-sectional epidemiological study.

Setting: Seventy-seven primary schools in four large regions in Greece.

Subjects: A sample of 1228 children having full data on total and visceral fat mass levels, as well as on anthropometric, dietary, physical activity, physical examination, socio-economic and perinatal indices, was examined.

Results: Maternal (OR=3.03 and 1.77) and paternal obesity (OR=1.62 and 1.78), maternal smoking during pregnancy $(\mathrm{OR}=1.72$ and 1.93) and rapid infant weight gain $(\mathrm{OR}=1.42$ and 1.96) were significantly and positively associated with children's increased total and visceral fat mass levels, respectively. Children's television watching for $>2 \mathrm{~h} / \mathrm{d}(\mathrm{OR}=1.40)$ and maternal pre-pregnancy obesity $(\mathrm{OR}=2 \cdot 46)$ were associated with children's increased total and visceral fat mass level, respectively. Furthermore, increased children's physical activity (OR $=0.66$ and 0.47 ) were significantly and negatively associated with children's total and visceral fat mass levels, respectively. Lastly, both father's age $>46$ years $(\mathrm{OR}=0.57)$ and higher maternal educational level $(\mathrm{OR}=0.45)$ were associated with children's increased total visceral fat mass level.

Conclusions: Parental sociodemographic characteristics, perinatal indices and pre-adolescent lifestyle behaviours were associated with children's abnormal levels of total and visceral fat mass. Any future programme for childhood prevention either from the perinatal age or at late childhood should take these indices into consideration.
\end{abstract}

The prevalence of childhood overweight and obesity has increased rapidly worldwide over the last decades and the rates are significantly higher in Southern compared with Northern European countries ${ }^{(1-3)}$. In Greece, $29 \cdot 9$ and $11.2 \%$ of children are overweight and obese, respectively ${ }^{(4)}$.

Childhood obesity has been associated with several health problems such as hypertension, dyslipidaemia and insulin resistance, which track into adulthood ${ }^{(5)}$. Several risk factors that increase childhood obesity have been separately identified, including parental anthropometric measures, lifestyle factors (i.e. dietary habits and physical activity levels) and sociodemographic indices ${ }^{(6)}$. Identification of these factors is very significant in order to improve our knowledge on the aetiology and to shape any future prevention programmes. However, childhood obesity has a multifactorial aetiology, which accentuates the need for studies highlighting the leading factors associated with childhood obesity within the sociodemographic, anthropometric and lifestyle characteristics of the family. Previously, our team identified several perinatal and parental characteristics as important risk factors for children's elevated $\mathrm{BMI}^{(7)}$. However, it is already reported that total and 
especially visceral fat mass is a more accurate indicator not only of childhood obesity but also for cardiometabolic risk than $\mathrm{BMI}^{(8)}$, rendering investigation of the determinants of elevated total and regional fat mass in children essential.

Thus, the aim of the current study was to examine the possible independent associations of perinatal, sociodemographic and lifestyle factors with childhood obesity estimated by total and visceral body fat.

\section{Materials and methods}

\section{Sampling}

The Healthy Growth Study is a cross-sectional epidemiological study initiated in May 2007. Approval to conduct the study was granted by the Greek Ministry of National Education and the Ethics Committee of the Harokopio University of Athens. The study population comprised schoolchildren attending the 5 th and 6 th grades of primary schools located in municipalities within the counties of Attica, Etoloakarnania, Thessaloniki and Iraklion. The sampling of schools was random, multistage and stratified by parental educational level and by the total population of students attending schools within the municipalities. The exact sampling methodology is described in detail elsewhere $^{(9)}$. An appropriate number of schools was randomly selected from each of these municipalities, in proportion to the population of schoolchildren registered in the 5th and 6th grades, on the basis of data obtained from the Greek Child Institute. All seventy-seven primary schools that were invited to participate in the present study responded positively. More specifically, an extended letter explaining the aims of the present study and a consent form for taking full measurements were provided to all parents or guardians having a child in the 5th and 6th grade in these schools. Parents who agreed to the participation of their children in the study had to sign the consent form and provide their contact details. Signed parental consent forms were collected for 2655 out of 4145 children (response rate $64.1 \%$ ). Complete socioeconomic, demographic and perinatal data (collected by the parents) and anthropometric data (measured in children) were collected for 2294 of the 2655 children ( $49.7 \%$ boys and $50.3 \%$ girls) whose parents had signed the consent forms (participation rate $86.4 \%$ ).

\section{Antbropometric measurements and definition of overweight and obesity}

Children underwent a physical examination by two trained members of the research team. The protocol and equipment used were the same in all schools. Weight was measured to the nearest $10 \mathrm{~g}$ using a digital scale (Seca Alpha, model 770; Seca, Hamburg, Germany). Pupils were weighed without shoes in the minimum clothing possible. Height was measured to the nearest $0 \cdot 1 \mathrm{~cm}$ using a commercial stadiometer (Leicester Height Measure; Invicta Plastics, Oadby, UK) with the pupil standing barefoot, keeping shoulders in a relaxed position, arms hanging freely and head in the Frankfort horizontal plane. Weight and height were used to calculate BMI. The International Obesity Task Force cut-off points ${ }^{(10)}$ were used to categorize participants as normal weight, overweight or obese.

\section{Assessment of percentage body fat and visceral fat mass}

Bioelectrical impedance analysis was used for the assessment of percentage body fat (Akkern BIA 101; Akkern Srl, Florence, Italy) and for abdominal-visceral fat mass (Viscan AB-140; Tanita, Kowloon, Hong Kong). In abdominal bioelectrical impedance analysis, an electric current is passed between the regions near the umbilicus and spinal cord at the umbilicus level, and the voltage generated in the lateral abdomen is recorded. Because the equipotential line that passes through visceral fat appears on the lateral abdominal surface, the amount of visceral fat can be estimated by measurement of the voltage generated at this location using a regression equation determined by computed tomography ${ }^{(11)}$. Participants were instructed to abstain from any food or liquid intake and from any intensive exercise for $4 \mathrm{~h}$ before measurement. They were also instructed not to wear any metal object during measurement. The assessments took place with the pupils lying on a non-conductive surface at ambient room temperature. Percentage body fat was calculated from the resistance and reactance values using valid equations derived from a similar pre-adolescent population. The equations used for this calculation were the following ${ }^{(12)}$. Boys:

$$
\begin{aligned}
\mathrm{FFM}= & -7 \cdot 13( \pm 2 \cdot 79)+\mathrm{Ht}^{2} / \mathrm{R} \times 0 \cdot 66( \pm 0 \cdot 07) \\
& +\mathrm{Xc} \times 0 \cdot 07( \pm 0 \cdot 02)+\mathrm{Ht} \times 0 \cdot 06( \pm 0 \cdot 03) \\
& +\mathrm{Wt} \times 0 \cdot 06( \pm 0 \cdot 03)
\end{aligned}
$$

Girls:

$$
\begin{aligned}
\mathrm{FFM}= & -0 \cdot 86( \pm 3 \cdot 40)+\mathrm{Ht}^{2} / \mathrm{R} \times 0 \cdot 46( \pm 0 \cdot 07) \\
& +\mathrm{Xc} \times 0 \cdot 04( \pm 0 \cdot 02)+\mathrm{Ht} \times 0 \cdot 05( \pm 0 \cdot 03) \\
& +\mathrm{Wt} \times 0 \cdot 14( \pm 0 \cdot 04)
\end{aligned}
$$

In the above, FFM is fat-free mass, $\mathrm{Ht}$ is height, $\mathrm{R}$ is resistance, $\mathrm{Xc}$ is reactance and $\mathrm{Wt}$ is weight. We first calculated fat free mass and, from the result of these equations, we calculated fat mass levels. Percentage trunk fat mass and visceral fat rating (rating scale from 1 to 59 units, with 0.5 increment) were read directly from the instrument. In the absence of valid and widely used thresholds for defining total and central adiposity in children, the third (highest) tertile of total (i.e. 24.53-34.02) and visceral (i.e. 3.00-5.13) fat mass levels were used as the key outcomes in the present study in order to identify the potential risk factors 
associated with these specific outcomes. As there were only two Tanita Viscan devices available, data on trunk-visceral fat mass were collected for a representative sub-sample of 1500 children. Taking missing values into consideration, the current study presents results on 1228 children having full total and visceral fat mass data, as well as anthropometric, dietary, physical activity, physical examination, socioeconomic and perinatal data.

\section{Family sociodemographic, parental weight status and perinatal data obtained by parents and birtb certificates}

Sociodemographic data, parental weight and height, and perinatal data were either reported by the parents or taken from the children's birth certificates and medical records that the parents were instructed to bring along during scheduled interviews. If parents were unable to attend (approximately $5 \%$ of the total sample), data were collected via telephone interviews and parents reported all necessary data using the birth certificates of their children. All interviews were conducted with the use of a standardized questionnaire by members of the research team who had been rigorously trained to minimize the interviewer effect. The information collected included: (i) father's and mother's age, which was grouped using tertiles; (ii) self-reported parental weight and height, from which BMI was calculated and used to categorize into underweight/normal weight, overweight and obese on the basis of the International Obesity Task Force cut-off points; (iii) parental years of education, which were stratified into $<9$ years ( 9 years being the duration of compulsory education in Greece that leads to a junior high school degree), 9-12 years (corresponds to having a high school degree), 12-16 years (corresponds to having a college or a university degree); and $>16$ years (corresponds to having a Master's or a $\mathrm{PhD}$ diploma)); (iv) parental and child nationality; (v) family type based on parental marital status (two-parent families, one-parent families); (vi) mean annual family income over the past 3 years, mother's current employment status and number of cars owned by the family; and (vii) household size $\left(\mathrm{m}^{2} /\right.$ family member). Mothers were asked to recall the following perinatal information: (i) type of conception (i.e. natural conception or in vitro fertilization); (ii) medical history of gestational diabetes mellitus and high blood pressure; (iii) smoking during pregnancy; (iv) weight before pregnancy and weight gained during pregnancy, based on the classification recommended by the US Institute of Medicine ${ }^{(13)}$; and (v) parity.

The following information was taken from each child's birth certificate and medical record: (i) birth date, this was used for the estimation of the exact age of each child; (ii) birth weight and gestational age for the classification into small for gestational age ( $<10$ th percentile), appropriate for gestational age (10th to 89th percentile) and large for gestational age ( $\geq 90$ th percentile); (iii) change in weight-for-length from birth to 6 months of age for the classification into poor $(Z$-score change $<-1)$, average $(Z$-score change $=-1$ to +1$)$ and rapid $(Z$-score change $>+1)$ weight gain during infancy; (vi) type of delivery (normal $v$. caesarean); and (v) feeding pattern from birth to 6 months of age (i.e. breast-feeding, age at which formula was introduced and solid food initiation).

\section{Dietary intake assessment}

Dietary intake data were obtained by trained dietitians and nutritionists via morning interviews with the children at the school site for two consecutive weekdays and one weekend day, using the $24 \mathrm{~h}$ recall technique. Specifically, all study participants were asked to describe the types and amounts of foods and beverages consumed during the previous day, provided that it was a usual day according to the participant's perception. To improve the accuracy of food description, standard household measures (cups, tablespoons, etc.) and food models were used to define amounts. At the end of each interview, the interviewers, who were dietitians rigorously trained to minimize the interviewer effect, reviewed the collected data with the respondent in order to clarify entries, servings and possible forgotten foods. Food intake data were analysed using the Nutritionist V diet analysis software (version 2.1, 1999; First Databank, San Bruno, CA, USA), which was extensively amended to include traditional Greek recipes ${ }^{(14)}$. Furthermore, the database was updated with nutritional information on processed foods provided by independent research institutes, food companies and fast-food chains. Daily energy intake was expressed as a percentage of estimated energy requirement.

\section{Breakfast consumption habits}

Using data from the $24 \mathrm{~h}$ recalls, the portions of each food group were distributed to meals during the day (i.e. breakfast, morning snack, lunch, afternoon snack, dinner, before-bed snack). We considered as breakfast the first things the participant ate and/or drank within $2 \mathrm{~h}$ after getting up in the morning. This could be at home, on the way to school or just before entering school. During the weekend, breakfast was considered as anything the participant drank and/or ate before 11.00 hours. Participants were considered as regular breakfast consumers based on whether they had breakfast on all three typical days as recorded from the $24 \mathrm{~h}$ recalls, whereas participants who did not have any portion of food and/or drink at breakfast on at least one out of three days were considered as irregular breakfast consumers ${ }^{(15)}$.

\section{Physical activity assessment}

\section{Step count}

To assess physical activity, study participants were provided with and instructed to wear a waist-mounted pedometer 
(Yamax SW-200 Digiwalker; Yamax Corporation Corporation, Tokyo, Japan) for 1 week (i.e. from Monday to Sunday). A number of approximately 200 pedometers were provided to the children in rotation. The pedometer was positioned in accordance with the manufacturer's instructions on the right waistband, vertically aligned with the patella. The pedometer used in the present study displayed the cumulative number of steps from the time it was worn in the morning until the time it was removed at bedtime. Participants were provided with a diary template and instructed to record the total number of daily steps displayed by the pedometer at bedtime and then zero the pedometer. Participants were also instructed to take off the pedometers when bathing or swimming and to record these activities in the diary. Finally, in cases where some children or adolescents forgot to wear the pedometer for a whole day, the relevant cells in the diary were left blank and the calculation for the mean daily number of steps was made using the appropriate number of days. For example, if a child had recorded steps for $7 \mathrm{~d}$, the mean daily number of steps was calculated by dividing the sum of steps recorded for the $7 \mathrm{~d}$ by 7 . If a child had recorded steps for $6 \mathrm{~d}$, the mean daily number of steps was calculated by dividing the sum of steps recorded for the $6 \mathrm{~d}$ by 6 .

\section{Screen time}

Children's screen time (i.e. time spent viewing television (TV)/videos and playing computer games) was assessed by children's report with regard to a usual weekday and a usual weekend. The mean daily screen time was calculated using the following equation:

$$
\begin{aligned}
\text { Daily screen time }= & {[(\text { weekday screen time } \times 2 \cdot 5)} \\
& + \text { weekend screen time }] / 7 .
\end{aligned}
$$

\section{Statistical analysis}

Gender differences were tested using either Student's $t$ test for continuous variables or the $\chi^{2}$ test and the two-sample $Z$-test for proportions for categorical variables. Furthermore, in order to examine the associations of perinatal, sociodemographic and behavioural indices with total and visceral fat mass levels, univariate logistic regression analyses were performed. In order to test whether the significant associations observed at a univariate level were independent, multivariate logistic regression analyses were also performed. Crude and adjusted odds ratios with 95\% confidence intervals were computed from the univariate and the multivariate regression analyses, respectively. Statistical power was set at $80 \%$ and statistical significance at $P=0.05$. The statistical software package IBM SPSS Statistics Version 21.0 was used for all analyses.

\section{Results}

Table 1 displays the mean values for age and certain anthropometric characteristics (weight, height, BMI) and body composition indices (total fat mass, visceral fat rating), resistance and reactance, and the prevalence of normal weight, overweight and obesity among children for the total sample and by gender. Overall, the mean age of children was 11.2 (SD 0.6) years and the observed prevalence was $30.9 \%$ for overweight and $11.4 \%$ for obesity. The prevalence of obesity was significantly higher in male than female children $(13.3 v .9 .6 \%, P<0.05)$. The mean resistance was $654.2(\mathrm{SD} 81 \cdot 8) \Omega$. The resistance was significantly higher in female than male children (673.9 (sD 85.1) v. 634.0 (sD 73.0) $\Omega, P=0.003$ ).

Table 2 presents the univariate associations of several perinatal factors with increased children's total fat mass

Table 1 Anthropometric characteristics, body composition indices and prevalence of overweight/obesity among 9-13-year-old children from

\begin{tabular}{|c|c|c|c|c|c|c|}
\hline & \multicolumn{2}{|c|}{ Boys (n 606) } & \multicolumn{2}{|c|}{ Girls (n 622) } & \multicolumn{2}{|c|}{ Total sample ( $n$ 1228) } \\
\hline & Mean & SD & Mean & SD & Mean & SD \\
\hline Age (years) & $11 \cdot 2$ & 0.6 & 11.2 & 0.6 & $11 \cdot 2$ & 0.6 \\
\hline Weight $(\mathrm{kg})$ & $45 \cdot 3$ & $10 \cdot 8$ & $45 \cdot 0$ & $11 \cdot 1$ & $45 \cdot 2$ & 10.9 \\
\hline Height $(\mathrm{cm})$ & 148 & 7.0 & 149 & 8.0 & 149 & 8.0 \\
\hline BMI $\left(\mathrm{kg} / \mathrm{m}^{2}\right)$ & $20 \cdot 4$ & 3.9 & $20 \cdot 1$ & 3.7 & $20 \cdot 3$ & $3 \cdot 8$ \\
\hline Resistance $(\Omega)$ & 634.0 & 73.0 & 673.9 & $85 \cdot 1$ & 654.2 & 81.8 \\
\hline Reactance $(\Omega)$ & 56.5 & 8.9 & $57 \cdot 6$ & $9 \cdot 1$ & $57 \cdot 1$ & 9.0 \\
\hline Total fat $(\%) \dagger$ & $28 \cdot 4$ & $9 \cdot 2$ & $29 \cdot 4$ & 9.6 & 28.4 & $9 \cdot 4$ \\
\hline \multirow[t]{2}{*}{ Visceral fat rating } & $3 \cdot 8$ & 0.2 & $2 \cdot 2$ & $0 \cdot 1$ & $4 \cdot 8$ & $3 \cdot 2$ \\
\hline & \multicolumn{2}{|c|}{$\%$} & \multicolumn{2}{|c|}{$\%$} & \multicolumn{2}{|c|}{$\%$} \\
\hline \multicolumn{7}{|l|}{ Weight groups } \\
\hline Normal weight & \multicolumn{2}{|c|}{$55 \cdot 2$} & \multicolumn{2}{|c|}{$60 \cdot 0$} & \multicolumn{2}{|c|}{$57 \cdot 6$} \\
\hline Overweight & \multicolumn{2}{|c|}{31.5} & \multicolumn{2}{|c|}{$30 \cdot 4$} & \multicolumn{2}{|c|}{30.9} \\
\hline Obese & \multicolumn{2}{|c|}{$13 \cdot 3$} & \multicolumn{2}{|c|}{$9 \cdot 6^{*}$} & \multicolumn{2}{|c|}{11.4} \\
\hline
\end{tabular}
four regions of Greece; Healthy Growth Study

*Statistically significant difference between genders $(P<0.05$, derived from the two-sample Z-test for proportions).

†Total fat was assessed using the resistance and reactance measurements provided by the Akkern BIA 101 device using the following equations: $\mathrm{FFM}=-7.13( \pm 2.79)+\mathrm{Ht}^{2} / \mathrm{R} \times 0.66( \pm 0.07)+\mathrm{Xc} \times 0.07( \pm 0.02)+\mathrm{Ht} \times 0.06( \pm 0.03)+\mathrm{Wt} \times 0.06( \pm 0.03) \quad($ boys $)$ and $\mathrm{FFM}=-0.86( \pm 3.40)+\mathrm{Ht} / \mathrm{R} \times 0.46( \pm 0.07)+\mathrm{Xc} \times 0.04( \pm 0.02)+$ $+\mathrm{Ht} \times 0.05( \pm 0.03)+\mathrm{Wt} \times 0.14( \pm 0.04)$ (girls). Fat-free mass was calculated and then fat mass was estimated. 
Table 2 Logistic regression analysis examining the associations between several perinatal factors (independent variables) and increased total and visceral fat mass levels (dependent variables) among 9-13-year-old children from four regions of Greece; Healthy Growth Study

\begin{tabular}{|c|c|c|c|c|c|c|}
\hline \multirow[b]{3}{*}{ Independent variable } & & & \multicolumn{4}{|c|}{ Dependent variable } \\
\hline & \multicolumn{2}{|c|}{ Cases } & \multicolumn{2}{|c|}{$\begin{array}{l}\text { Increased total fat mass } \\
\text { (third tertile } \dagger \text { ) }\end{array}$} & \multicolumn{2}{|c|}{$\begin{array}{l}\text { Increased visceral fat mass } \\
\text { (third tertile } \dagger \text { ) }\end{array}$} \\
\hline & $n$ & $\%$ of total & OR & $95 \% \mathrm{Cl}$ & OR & $95 \% \mathrm{Cl}$ \\
\hline \multicolumn{7}{|l|}{ Type of conception } \\
\hline Normal & 1192 & $97 \cdot 1$ & \multicolumn{2}{|c|}{1.00} & \multicolumn{2}{|c|}{1.00} \\
\hline IVF & 36 & 2.9 & 0.55 & $0.22,1.33$ & 1.09 & $0.51,2.35$ \\
\hline \multicolumn{7}{|l|}{ Mother's pre-pregnancy weight status } \\
\hline Normal weight & 932 & $75 \cdot 9$ & \multicolumn{2}{|c|}{1.00} & \multicolumn{2}{|c|}{1.00} \\
\hline Underweight & 87 & $7 \cdot 1$ & 0.67 & $0.37,1.19$ & 0.73 & $0.40,1.32$ \\
\hline Overweight & 170 & $13 \cdot 8$ & 2.03 & $1.44,2.86$ & 2.02 & $1.42,2.87$ \\
\hline Obese & 39 & 3.2 & 3.73 & $1.95,7.13$ & 4.44 & $2.32,8.50$ \\
\hline \multicolumn{7}{|l|}{ Gestational weight gain } \\
\hline Within IOM recommendation & 406 & 33.1 & \multicolumn{2}{|c|}{1.00} & \multicolumn{2}{|c|}{1.00} \\
\hline Below IOM recommendation & 439 & 35.7 & 0.84 & $0.61,1.15$ & 0.83 & $0.60,1.15$ \\
\hline Above IOM recommendation & 383 & $31 \cdot 2$ & 1.36 & $1.00,1.85$ & 1.08 & $0.78,1.49$ \\
\hline \multicolumn{7}{|l|}{ Maternal smoking during pregnancy } \\
\hline No smoking & 1038 & 84.5 & \multicolumn{2}{|c|}{1.00} & \multicolumn{2}{|c|}{1.00} \\
\hline Smoking at any one or two trimesters & 76 & $6 \cdot 2$ & 1.79 & $1 \cdot 10,2.92$ & $1 \cdot 19$ & $0.69,2.04$ \\
\hline All trimesters & 114 & $9 \cdot 3$ & 1.73 & $1.15,2.60$ & 2.08 & $1.39,3.13$ \\
\hline \multicolumn{7}{|l|}{ High blood pressure during pregnancy } \\
\hline No & 1172 & 95.4 & \multicolumn{2}{|c|}{1.00} & \multicolumn{2}{|c|}{1.00} \\
\hline Yes & 35 & $2 \cdot 9$ & $1 \cdot 12$ & $0.53,2.36$ & 0.98 & $0 \cdot 44,2 \cdot 17$ \\
\hline Not known & 21 & $1 \cdot 7$ & 1.12 & $0.43,2.92$ & 1.65 & $0.66,4.12$ \\
\hline Diabetes mellitus during pregnancy & & & & & & \\
\hline No & 1169 & $95 \cdot 2$ & & & & \\
\hline Yes & 33 & 2.7 & 0.89 & $0.40,2.00$ & 0.73 & $0.30,1.78$ \\
\hline Not known & 26 & $2 \cdot 1$ & 1.03 & $0.43,2.46$ & 1.45 & $0.62,3.38$ \\
\hline Gestational age (weeks) & & & & & & \\
\hline$<37$ & 261 & $21 \cdot 3$ & & & & \\
\hline$\geq 37$ & 967 & 78.7 & 1.02 & $0.75,1.40$ & 0.98 & $0.71,1.35$ \\
\hline Parity & & & & & & \\
\hline Uniparous & 615 & $50 \cdot 1$ & & & & \\
\hline Multiparous & 613 & 49.9 & 0.91 & $0.71,1.17$ & 1.02 & $0.79,1.33$ \\
\hline Birth weight for gestational age & & & & & & \\
\hline Appropriate (10th-89th percentile) & 994 & $80 \cdot 9$ & & & & \\
\hline Small ( $<10$ th percentile) & 142 & 11.6 & $1 \cdot 18$ & $0.80,1.74$ & 1.06 & $0.71,1.60$ \\
\hline Large (>90th percentile) & 92 & $7 \cdot 5$ & 0.83 & $0.50,1.38$ & 0.85 & $0.50,1.43$ \\
\hline Type of delivery & & & & & & \\
\hline Normal & 889 & $72 \cdot 4$ & & & & \\
\hline Caesarean & 339 & $27 \cdot 6$ & $1 \cdot 10$ & $0.83,1.46$ & 1.01 & $0.75,1.36$ \\
\hline Weight gain in the first 6 months & & & & & & \\
\hline Average $(Z$-score change $=-1$ to +1$)$ & 694 & $56 \cdot 5$ & & & & \\
\hline Poor $(Z$-score change $<-1)$ & 141 & 11.5 & $1 \cdot 12$ & $0.74,1.70$ & 1.16 & $0.74,1.81$ \\
\hline Rapid (Z-score change > +1) & 393 & $32 \cdot 0$ & 1.52 & $1.15,2.00$ & 2.05 & $1.54,2.73$ \\
\hline Breast-feeding & & & & & & \\
\hline Not exclusive & 1126 & 91.7 & & & & \\
\hline Exclusive & 102 & $8 \cdot 3$ & 0.90 & $0.56,1.44$ & 0.73 & $0.44,1.22$ \\
\hline Time of solid food initiation & & & & & & \\
\hline$\leq 4$ months & 209 & $17 \cdot 0$ & & & & \\
\hline 5-6 months & 837 & $68 \cdot 2$ & 1.25 & $0.88,1.79$ & 1.41 & $0.97,2.07$ \\
\hline$>6$ months & 182 & 14.8 & 1.24 & $0.78,1.96$ & 1.59 & $1.01,2.26$ \\
\hline
\end{tabular}

IVF, in vitro fertilization; IOM, Institute of Medicine.

Bold font indicates statistically significant OR $(P<0.05)$.

$\mathrm{OR}$ and $95 \% \mathrm{Cl}$ derived from univariate logistic regression models, i.e. with its model including one perinatal variable as independent variable and the highest total or visceral fat mass level as dependent variable.

$\dagger$ †s no specific and widely used cut-off points for total and visceral fat mass are available, the third tertiles of children with the highest levels with total and visceral fat mass were used as independent variables.

and visceral fat mass rating (i.e. third tertile). Children whose mothers were overweight or obese before pregnancy were more likely to have increased total fat mass $(\mathrm{OR}=2 \cdot 03 ; 95 \%$ CI $1.44,2.86$ and $\mathrm{OR}=3.73 ; 95 \% \mathrm{CI} 1.95$, $7 \cdot 13$, respectively) and visceral fat mass rating $(\mathrm{OR}=2 \cdot 02$; $95 \%$ CI $1.42,2.87$ and $\mathrm{OR}=4.44 ; 95 \%$ CI $2 \cdot 32,8 \cdot 50$, respectively) compared with children whose mothers were within the normal weight range before pregnancy. Regarding maternal smoking during pregnancy, children whose mothers were smoking at any one or two trimesters of pregnancy were more likely to have increased total fat mass rating $(\mathrm{OR}=1.79 ; 95 \% \mathrm{CI} 1 \cdot 10,2 \cdot 92)$ compared with 
children born to mothers who were not smoking during pregnancy; moreover, children whose mothers were smoking during all trimesters of pregnancy were more likely to have increased total fat mass and visceral fat mass rating $(\mathrm{OR}=1 \cdot 73 ; 95 \% \mathrm{CI} 1 \cdot 15,2.60$ and $\mathrm{OR}=2 \cdot 08 ; 95 \%$ CI $1 \cdot 39,3 \cdot 13$, respectively) than children born to mothers who were not smoking during pregnancy. As far as weight gain during the first 6 months of age is concerned, rapid weight gain was found to increase the likelihood of children's increased total fat mass and visceral fat mass rating $(\mathrm{OR}=1.52 ; 95 \% \mathrm{CI} 1.15,2.00$ and $\mathrm{OR}=2.05 ; 95 \%$ CI 1.54 , 2.73 , respectively) compared with children who had average weight gain during this time. Regarding time of solid food initiation, introducing solid food to children's diet after the 6th month of age was found to increase the likelihood of higher visceral fat mass rating $(\mathrm{OR}=1.59$; $95 \%$ CI 1.01, 2.26) compared with solid food initiation before or at the 4 th month of age.

Table 3 presents the univariate associations of parental anthropometrics, family sociodemographics, dietary and physical activity indices with increased children's total fat mass and visceral fat mass rating (i.e. third tertile). Regarding age categories, children in the age group of 11-13 years were more likely $(\mathrm{OR}=1 \cdot 42 ; 95 \%$ CI 1.09, 1.86) to be in the highest tertile of total body fat mass compared with children in the age group of 9-11 years. Regarding parental anthropometrics, having overweight and obese parents (either mother or father) was found to increase the odds for children's higher fat mass levels and visceral fat mass rating. Regarding family sociodemographic characteristics, children whose father was $>46$ years old were less likely $(\mathrm{OR}=0.68$; $95 \%$ CI $0.50,0.95)$ to have increased total fat mass levels than children having a younger ( $<42$ years old) father. Furthermore, paternal and maternal educational level $>12$ years, compared with $<9$ years, was found to decrease the odds for children's higher fat mass levels and visceral fat mass rating. Regarding breakfast consumption, children who consumed breakfast had decreased likelihood of having increased total fat mass and visceral fat mass rating $(\mathrm{OR}=0.56 ; 95 \% \mathrm{CI} 0.42$, 0.74 and $\mathrm{OR}=0.58 ; 95 \% \mathrm{CI} 0.44,0.76$, respectively) than irregular breakfast consumers. Concerning physical activity, children who watched TV for $>2 \mathrm{~h} / \mathrm{d}$ were more likely to have increased visceral fat mass rating $(\mathrm{OR}=1.35$; $95 \%$ CI 1.05, 1.75) than children who watched TV for $<2 \mathrm{~h} / \mathrm{d}$, while girls who had $\geq 12000$ steps per day and boys who had $\geq 13000$ steps per day were less likely to have increased total fat mass and visceral fat mass rating $(\mathrm{OR}=0.45 ; 95 \%$ CI 0.34, 0.60 and $\mathrm{OR}=0.63 ; 95 \%$ CI 0.48, $0 \cdot 81$, respectively) compared with their counterparts who had fewer daily steps.

Table 4 presents the multivariate associations between those perinatal, anthropometric, family sociodemographic, dietary and physical activity indices that were found to be significantly associated with total fat mass and visceral fat mass rating at a univariate level. Maternal smoking during pregnancy $(\mathrm{OR}=1 \cdot 72 ; 95 \% \mathrm{CI} 1 \cdot 06,2 \cdot 80)$, rapid weight gain in the first 6 months $(\mathrm{OR}=1.42 ; 95 \% \mathrm{CI} 1.03,1.97)$, maternal $(\mathrm{OR}=3.03 ; 95 \% \mathrm{CI} 1.76,5.23)$ and paternal obesity (OR $=1.62 ; 95 \% \mathrm{CI} 1.04,2.54)$ and watching TV for $>2 \mathrm{~h} / \mathrm{d}(\mathrm{OR}=1.40 ; 95 \% \mathrm{CI} 1.03,1.90)$ remained significantly and positively associated with children's increased total fat mass levels. Furthermore, maternal prepregnancy obese weight status (OR 2.46; 95\% CI 1.02, $5.90)$, maternal smoking during pregnancy $(\mathrm{OR}=1.93$; $95 \%$ CI $1 \cdot 19,3 \cdot 13)$, rapid weight gain in the first 6 months $(\mathrm{OR}=1.96 ; 95 \%$ CI $1.41,2 \cdot 72)$, maternal $(\mathrm{OR}=1.77 ; 95 \%$ CI $1.01,3 \cdot 10)$ and paternal obesity $(\mathrm{OR}=1.78 ; 95 \% \mathrm{CI}$ $1 \cdot 12,2 \cdot 83)$ remained significantly and positively associated with children's increased visceral fat mass levels. On the other hand, father's age $>46$ years $(\mathrm{OR}=0.57$; $95 \% \mathrm{CI}$ $0.39,0.83)$, maternal educational level of 9-12 years $(\mathrm{OR}=0.62 ; 95 \% \mathrm{CI} 0.41,0.94)$ and $12-16$ years $(\mathrm{OR}=0.53$; $95 \%$ CI $0.33,0.86)$ and daily steps $\geq 12000$ for girls and $\geq 13000$ for boys (OR $=0.66$; $95 \%$ CI 0.49, 0.89) remained significantly and negatively associated with children's total fat mass levels. Finally, maternal educational level of $12-16$ years $(\mathrm{OR}=0.58 ; 95 \% \mathrm{CI} 0 \cdot 36,0.94)$ and $>16$ years $(\mathrm{OR}=0.45 ; 95 \% \mathrm{CI} 0 \cdot 22,0.95)$ and daily steps $\geq 12000$ for girls and $\geq 13000$ for boys (OR $=0.47$; $95 \%$ CI $0.34,0 \cdot 64$ ) remained significantly and negatively associated with children's visceral fat mass levels.

\section{Discussion}

The current study sought to examine the possible independent associations of perinatal, sociodemographic and lifestyle characteristics with childhood obesity, assessed as total and visceral body fat, using data from a large, cross-sectional epidemiologic study: the Healthy Growth Study.

Results regarding obesity prevalence in our population show that childhood obesity in Greece is very high, as $31.5 \%$ of boys and $30.4 \%$ of girls were overweight and $13.3 \%$ of boys and $9.6 \%$ of girls were obese. Unfortunately there are no national estimates of childhood obesity in Greece, but another large epidemiological study conducted in 4786 children aged 10-12 years old showed similar obesity prevalence rates (29.9) and $29.2 \%$ for overweight and 12.9 and $10.6 \%$ for obesity in boys and girls, respectively) ${ }^{(16)}$

Maternal overweight and obesity before pregnancy were found to be the strongest perinatal predictors of childhood elevated total and visceral fat mass in the present study. Many previous studies have shown the association of maternal weight before pregnancy with childhood obesity. More specifically, Franca-Neto et al. ${ }^{(17)}$ showed a positive association between mother's pre-pregnancy higher waist circumference and child's subcutaneous and visceral fat in a study of 116 mother and child dyads. Overweight and obese pregnant women are more likely to have insulin resistance, even those with normal glucose tolerance, compared with 
Table 3 Logistic regression analysis examining the associations between parental anthropometric, family sociodemographic and children's dietary and physical activity indices (independent variables) and increased total and visceral fat mass levels (dependent variables) among 9-13-year-old children from four regions of Greece; Healthy Growth Study

\begin{tabular}{|c|c|c|c|c|c|c|}
\hline \multirow[b]{3}{*}{ Independent variable } & & & \multicolumn{4}{|c|}{ Dependent variable } \\
\hline & \multicolumn{2}{|c|}{ Cases } & \multicolumn{2}{|c|}{$\begin{array}{l}\text { Increased total fat mass } \\
\text { (third tertile } \dagger)\end{array}$} & \multicolumn{2}{|c|}{$\begin{array}{l}\text { Increased visceral fat mass } \\
\text { (third tertile })\end{array}$} \\
\hline & $n$ & $\%$ of total & OR & $95 \% \mathrm{Cl}$ & OR & $95 \% \mathrm{Cl}$ \\
\hline \multicolumn{7}{|l|}{ Child's sex } \\
\hline Girl & 622 & $50 \cdot 7$ & \multicolumn{2}{|c|}{1.00} & \multicolumn{2}{|c|}{1.00} \\
\hline Boy & 606 & $49 \cdot 3$ & 0.94 & $0.73,1.21$ & 0.82 & $0.63,1.07$ \\
\hline \multicolumn{7}{|l|}{ Age category } \\
\hline $9-11$ years & 484 & 39.4 & \multicolumn{2}{|c|}{1.00} & \multicolumn{2}{|c|}{1.00} \\
\hline $11-13$ years & 744 & $60 \cdot 6$ & 1.42 & $1.09,1.86$ & 1.30 & $0.99,1.71$ \\
\hline \multicolumn{7}{|l|}{ Mother’s BMI¥ } \\
\hline Underweight/normal weight & 751 & $61 \cdot 2$ & & & & \\
\hline Overweight & 343 & 27.9 & 1.46 & $1.08,1.97$ & 1.47 & $1.10,1.97$ \\
\hline Obese & 134 & $10 \cdot 9$ & 3.03 & $2.05,4.46$ & 3.84 & $2.62,5.62$ \\
\hline Father's BMI & & & & & & \\
\hline Underweight/normal weight & 286 & 23.4 & & & & \\
\hline Overweight & 677 & 55.4 & 1.31 & $0.92,1.85$ & 1.22 & $0.88,1.69$ \\
\hline Obese & 260 & 21.3 & 1.95 & $1.31,2.91$ & 1.81 & $1.24,2.65$ \\
\hline Nationality & & & & & & \\
\hline Non-Greek & 1107 & $90 \cdot 1$ & & & & \\
\hline Greek & 121 & 9.9 & $1 \cdot 10$ & $0.71,1.69$ & 1.07 & $0.69,1.68$ \\
\hline Family status & & & & & & \\
\hline Two-parent family & 1101 & 90.5 & & & & \\
\hline Single-parent family & 116 & 9.5 & 0.92 & $0.59,1.43$ & 1.21 & $0.78,1.87$ \\
\hline Father's age & & & & & & \\
\hline$<42$ years & 421 & 34.4 & & & & \\
\hline $42-46$ years & 428 & $35 \cdot 0$ & 0.90 & $0.67,1.22$ & 0.86 & $0.63,1 \cdot 18$ \\
\hline$>46$ years & 374 & $30 \cdot 6$ & 0.68 & $0.50,0.95$ & 0.89 & $0.64,1.23$ \\
\hline Mother's age & & & & & & \\
\hline$<38$ years & 449 & $36 \cdot 6$ & & & & \\
\hline $38-42$ years & 438 & 35.7 & 1.00 & $0.74,1.35$ & 1.12 & $0.82,1.53$ \\
\hline$>42$ years & 341 & $27 \cdot 8$ & 0.94 & $0.68,1.29$ & 1.21 & $0.87,1.68$ \\
\hline Family income ( $€$ /year) & & & & & & \\
\hline$<12000$ & 223 & 19.8 & & & & \\
\hline $12000-30000$ & 555 & $49 \cdot 2$ & 0.97 & $0.69,1.37$ & 0.87 & $0.61,1.24$ \\
\hline$>30000$ & 350 & 31.0 & 0.80 & $0.55,1.16$ & 0.73 & $0.49,1.08$ \\
\hline Paternal education & & & & & & \\
\hline$<9$ years & 322 & $26 \cdot 2$ & & & & \\
\hline $9-12$ years & 460 & 37.5 & 0.96 & $0.70,1.32$ & 0.87 & $0.63,1.21$ \\
\hline $12-16$ years & 305 & $24 \cdot 8$ & 0.65 & $0.45,0.93$ & 0.64 & $0.44,0.93$ \\
\hline$>16$ years & 141 & 11.5 & 0.70 & $0.44,1.11$ & 0.54 & $0.32,0.89$ \\
\hline Maternal education & & & & & & \\
\hline$<9$ years & 260 & $21 \cdot 2$ & & & & \\
\hline $9-12$ years & 478 & 38.9 & 0.72 & $0.52,1.00$ & 0.74 & $0.53,1.04$ \\
\hline $12-16$ years & 386 & 31.4 & 0.55 & $0.39,0.79$ & 0.53 & $0.37,0.77$ \\
\hline$>16$ years & 104 & 8.5 & 0.66 & $0.40,1.11$ & 0.44 & $0.29,0.89$ \\
\hline Maternal employment status & & & & & & \\
\hline Unemployed & 403 & $32 \cdot 8$ & & & & \\
\hline Employed & 825 & $67 \cdot 2$ & 0.86 & $0.66,1.13$ & 0.93 & $0.70,1.23$ \\
\hline Household size ( $\mathrm{m}^{2} /$ family member) & & & & & & \\
\hline$<20$ & 425 & $36 \cdot 2$ & & & & \\
\hline $20-25$ & 299 & $25 \cdot \overline{5}$ & 0.89 & $0.64,1.25$ & 1.14 & $0.80,1.61$ \\
\hline $25-30$ & 228 & $19 \cdot 4$ & 1.20 & $0.84,1.71$ & 1.26 & $0.87,1.83$ \\
\hline$>30$ & 222 & 18.9 & 1.05 & $0.73,1.51$ & 1.16 & $0.79,1.70$ \\
\hline Family cars & & & & & & \\
\hline 0 & 118 & $9 \cdot 6$ & & & & \\
\hline 1 & 635 & $51 \cdot 7$ & 1.43 & $0.90,2.29$ & 1.62 & $0.99,2.66$ \\
\hline 2 & 430 & $35 \cdot 0$ & $1 \cdot 10$ & $0.68,1.80$ & 1.03 & $0.61,1.73$ \\
\hline$\geq 3$ & 45 & 3.7 & 1.44 & $0.66,3.13$ & 1.59 & $0.71,3.56$ \\
\hline Breakfast consumption & & & & & & \\
\hline No & 346 & $28 \cdot 3$ & & & & \\
\hline Yes & 876 & 71.7 & 0.56 & $0.42,0.74$ & 0.58 & $0.44,0.76$ \\
\hline Television time & & & & & & \\
\hline$<2 \mathrm{~h} / \mathrm{d}$ & 633 & $52 \cdot 4$ & & & & \\
\hline$>2 \mathrm{~h} / \mathrm{d}$ & 575 & $47 \cdot 6$ & 1.30 & $1.00,1.70$ & 1.35 & $1.05,1.75$ \\
\hline Physical activity levels & & & & & & \\
\hline$<12000$ steps/d (girls), <13000 step/d (boys) & 638 & $52 \cdot 0$ & & & & \\
\hline$\geq 12000 \mathrm{steps} / \mathrm{d}$ (girls), $\geq 13000 \mathrm{steps} / \mathrm{d}$ (boys) & 590 & $48 \cdot 0$ & 0.45 & $0.34,0.60$ & 0.63 & $0.48,0.81$ \\
\hline
\end{tabular}

Bold font indicates statistically significant $\mathrm{OR}(P<0.05)$.

$\mathrm{OR}$ and $95 \% \mathrm{Cl}$ derived from univariate logistic regression models, i.e. with its model including one parental anthropometric, family sociodemographic or children's dietary or physical activity variable as independent variable and highest total or visceral fat mass level as dependent variable.

$\dagger$ †s no specific and widely used cut-off points for total and visceral fat mass are available, the third tertiles of children with the highest levels with total and visceral fat mass were used as independent variables.

†Based on recommendations by the Institute of Medicine ${ }^{(13)}$. 
Table 4 Multiple logistic regression models examining the associations between perinatal data, parental anthropometrics, family sociodemographic and children's dietary and physical activity indices (independent variables) and increased total and visceral fat mass levels (dependent variables) among 9-13-year-old children from four regions of Greece; Healthy Growth Study

\begin{tabular}{|c|c|c|c|c|}
\hline \multirow[b]{3}{*}{ Independent variable } & \multicolumn{4}{|c|}{ Dependent variable } \\
\hline & \multicolumn{2}{|c|}{ Model 1: total fat mass (third tertile†) } & \multicolumn{2}{|c|}{ Model 2: visceral fat mass (third tertile $\dagger$ ) } \\
\hline & OR & $95 \% \mathrm{Cl}$ & OR & $95 \% \mathrm{Cl}$ \\
\hline \multicolumn{5}{|l|}{ Age category } \\
\hline $9-11$ years & \multicolumn{2}{|c|}{1.00} & \multicolumn{2}{|c|}{1.00} \\
\hline $11-13$ years & 1.31 & $0.95,1.78$ & 1.18 & $0.86,1.62$ \\
\hline \multicolumn{5}{|l|}{ Mother's pre-pregnancy weight status } \\
\hline Normal weight & \multicolumn{2}{|c|}{1.00} & \multicolumn{2}{|c|}{1.00} \\
\hline Underweight & 0.59 & $0.30,1 \cdot 19$ & 0.62 & $0.30,1.27$ \\
\hline Overweight & 1.31 & $0.83,2.08$ & 1.53 & $0.96,2.44$ \\
\hline Obese & 1.39 & $0.58,3.33$ & 2.46 & $1.02,5.90$ \\
\hline \multicolumn{5}{|l|}{ Maternal smoking during pregnancy } \\
\hline No smoking & \multicolumn{2}{|c|}{1.00} & \multicolumn{2}{|c|}{1.00} \\
\hline Smoking at any one or two trimesters & 1.52 & $0.85,2 \cdot 71$ & 0.81 & $0.43,1.53$ \\
\hline All trimesters & 1.72 & $1.06,2.80$ & 1.93 & $1.19,3 \cdot 13$ \\
\hline \multicolumn{5}{|l|}{ Weight gain in the first 6 months } \\
\hline Average ( $Z$-score change $=-1$ to +1$)$ & \multicolumn{2}{|c|}{1.00} & \multicolumn{2}{|c|}{1.00} \\
\hline Poor $(Z$-score change $<-1)$ & 0.98 & $0.60,1.59$ & 1.01 & $0.61,1.67$ \\
\hline Rapid (Z-score change $>+1$ ) & 1.42 & $1.03,1.97$ & 1.96 & $1.41,2.72$ \\
\hline \multicolumn{5}{|l|}{ Timing of solid food initiation } \\
\hline$\leq 4$ months & \multicolumn{2}{|c|}{1.00} & \multicolumn{2}{|c|}{1.00} \\
\hline 5-6 months & $1 \cdot 18$ & $0.78,1.79$ & 1.43 & $0.92,2 \cdot 22$ \\
\hline$>6$ months & 1.41 & $0.82,2.42$ & 1.72 & $0.98,3.03$ \\
\hline \multicolumn{5}{|l|}{ Father's age } \\
\hline$<42$ years & & & & \\
\hline $42-46$ years & 0.83 & $0.58,1.18$ & 0.83 & $0.57,1.20$ \\
\hline$>46$ years & 0.57 & $0.39,0.83$ & 0.81 & $0.55,1.19$ \\
\hline Mother’s BMI¥ & & & & \\
\hline Normal weight & & & & \\
\hline Overweight & 1.31 & $0.91,1.88$ & 1.28 & $0.88,1.86$ \\
\hline Obese & 3.03 & $1.76,5.23$ & 1.77 & $1.01,3 \cdot 10$ \\
\hline Father's BMI & & & & \\
\hline Normal weight & & & & \\
\hline Overweight & 1.24 & $0.84,1.83$ & 1.32 & $0.88,1.98$ \\
\hline Obese & 1.62 & $1.04,2.54$ & 1.78 & $1.12,2.83$ \\
\hline Paternal education & & & & \\
\hline$<9$ years & & & & \\
\hline $9-12$ years & 1.31 & $0.87,1.96$ & 1.08 & $0.72,1.62$ \\
\hline $12-16$ years & 1.19 & $0.73,1.94$ & 1.09 & $0.66,1.78$ \\
\hline$>16$ years & 1.83 & $0.96,3.49$ & 1.24 & $0.63,2.44$ \\
\hline Maternal education & & & & \\
\hline$<9$ years & & & & \\
\hline $9-12$ years & 0.62 & $0.41,0.94$ & 0.67 & $0.44,1.03$ \\
\hline $12-16$ years & 0.53 & $0.33,0.86$ & 0.58 & $0.36,0.94$ \\
\hline$>16$ years & 0.58 & $0.29,1.16$ & 0.45 & $0.22,0.95$ \\
\hline Television time & & & & \\
\hline$<2 \mathrm{~h} / \mathrm{d}$ & & & & \\
\hline$>2 \mathrm{~h} / \mathrm{d}$ & 1.40 & $1.03,1.90$ & 1.34 & $0.98,1.82$ \\
\hline Physical activity level & & & & \\
\hline$<12000$ steps/d (girls), <13000 steps/d (boys) & & & & \\
\hline$\geq 12000$ steps/d (girls), $\geq 13000$ steps/d (boys) & 0.66 & $0.49,0.89$ & 0.47 & $0.34,0.64$ \\
\hline Breakfast consumption & & & & \\
\hline No & & & & \\
\hline Yes & 0.83 & $0.60,1.14$ & 0.81 & $0.59,1.12$ \\
\hline
\end{tabular}

Bold font indicates statistically significant $\mathrm{OR}(P<0.05)$.

Adjustment was made for dietary energy intake.

Adjusted OR and $95 \% \mathrm{Cl}$ were derived from multivariate logistic regression models, i.e. with its model including one perinatal, parental anthropometric, family sociodemographic or children's dietary or physical activity variable as independent variable and highest total or visceral fat mass level as dependent variable. †As no specific and widely used cut-off points for total and visceral fat mass are available, the third tertiles of children with the highest levels with total and visceral fat mass were used as independent variables.

$\ddagger$ 殒ased on recommendations by the Institute of Medicine ${ }^{(13)}$.

lean or average-weight pregnant women ${ }^{(18)}$. As a result of insulin resistance, there is a greater availability of glucose and lipids, the energy sources and substrates for fetoplacental growth $^{(19)}$. In the study of Catalano et al. ${ }^{(20)}$ results strongly supported the argument that maternal pre-pregnancy obesity is a significant risk factor for childhood obesity and that 
obesity may be programmed in utero through the adverse metabolic status of obese mothers. One hypothesis is that during pregnancy of an obese mother, pathways for intracellular lipid biosynthesis are selectively up-regulated ${ }^{(19)}$.

Another risk factor found to be associated with increased visceral fat and total body fat in the present children was the growth rate during infancy. In particular, rapid weight gain during the first 6 months and until 2 years of age was found to increase the likelihood of higher total body and visceral fat mass compared with normal development. The association of rapid weight gain during the first half-year of infancy with overweight in childhood or adolescence has been constantly reported in a plethora of studies ${ }^{(21-25)}$. Related reviews have shown a significant association of rapid growth in early life with overweight or obesity in subsequent life stages ${ }^{(26-28)}$, although different exposures (various definitions and timings of rapid weight gain, linear growth) and various outcomes (continuous BMI, obesity/overweight, weight) were used in these four systematic reviews. Overall, data support a hypothesis called the 'growth acceleration hypothesis', which proposes that early nutrition and growth rate make a major contribution to obesity and other components of the metabolic syndrome, such as hypertension or dyslipidaemia, that predispose to cardiovascular morbidity and mortality ${ }^{(29)}$.

In the present study, smoking during pregnancy was also positively associated with total and visceral fat mass in children. Smoking in pregnancy has been suggested as further supporting the theory of the 'fetal origins of adult diseases', as there are several studies showing an association between maternal smoking during pregnancy and overweight in children that could also be justified via low birth weight caused by maternal smoking ${ }^{(30-34)}$. Only a few studies have assessed fat accumulation rather than BMI in order to determine overweight ${ }^{(35-37)}$. BMI is a less accurate assessment index of adiposity, especially in children, compared with body fat distribution. Von Schnurbein and co-workers ${ }^{(38)}$ showed a positive association between maternal smoking during pregnancy and higher proportion of visceral fat in children. Additionally, no association of smoking with fat distribution was found in early puberty, whereas in late puberty, maternal smoking was associated with both higher subcutaneous and intra-abdominal fat mass $^{(39)}$. Most recently, in the KOALA Birth Cohort Study ${ }^{(40)}$ maternal smoking during pregnancy was associated with lower birth weight and higher weight gain in the first year after birth, even exceeding the initial birth weight deficit. Children had a higher risk of exceeding the 85th percentile of waist circumference, but not central-to-peripheral skinfold thickness ratio. Results herein confirm the positive association of maternal smoking with higher total fat mass in children. A possible mechanism underlying the association between smoking during pregnancy and increased children's adiposity/body weight is abnormal regulation of central endocrine control of body weight homeostasis, particularly abnormal hypothalamic regulation of appetite and energy expenditure ${ }^{(41,42)}$.

Besides perinatal factors, higher socio-economic factors were inversely associated with childhood obesity or increased total body fat in the current study. Parental higher educational level and particularly maternal educational level showed a negative association with occurrence of childhood obesity, higher total body fat and visceral body fat mass levels. Results herein are in accordance with previous data. For example, in a study by von Schnurbein et $a{ }^{(38)}$ of 1046 children, a negative association between maternal education and high levels of visceral fat in children was reported. A possible explanation would be that parental high educational level entails a better knowledge and understanding of the impact of systemic and increased physical activity or consumption of fruits, vegetables and whole grains $v$. high-energy diet though poor in nutrient content.

Regarding parental BMI, parental obesity in the present study was positively associated with the occurrence of high levels of total body and visceral body fat mass in children, in line with other surveys ${ }^{(38,43)}$. Apart from the inherited genetic risk, children who grow up with obese parents are more likely to adapt their parents' eating behaviour and sedentary physical activity that further contribute to the obesity phenotype.

In the present study, another important factor associated with childhood obesity was the time spent by children watching TV. It was found that watching TV for $>2 \mathrm{~h} / \mathrm{d}$ is associated with elevated total fat mass in children. As shown previously in 369 children and adolescents having a bedroom TV, TV viewing time is related to high waist circumference, fat mass and abdominal subcutaneous adiposity $^{(44)}$. Evidently, a negative association between steps per day ( $\geq 12000$ steps for girls and $\geq 13000$ steps for boys) and increased total and visceral body fat was found in the present study, which is in agreement with other studies. Specifically, visceral abdominal fat was associated with elevated whole-body fat and more sedentary activities among 8-year-old children at risk of obesity ${ }^{(45)}$. Additionally, food company advertisements also have a significant contribution to these associations, as they predominantly promote foods high in sugar, fat and/or salt $^{(46,47)}$.

Judging from the overall findings, the present study showed that some of the independent variables tested were significantly associated with total fat mass level while others with visceral fat mass rating. Although in many cases increased total body fat mass also reflects increased visceral fat mass level, this is not always the case, since in many individuals increased total body fat mass level may reflect mainly high subcutaneous fat mass level. Considering the above, as well as the fact that in the present study total body and visceral fat mass were measured by two different devices, observing significant associations with total body fat mass levels is not a 
prerequisite of finding significant associations also with visceral fat mass levels or vice versa.

The findings of the present study should be interpreted under the light of its strengths and limitations. Regarding strengths, the Healthy Growth Study was a large-scale epidemiological study conducted using a representative sample of children from four prefectures within the wider region of Greece. However, one of the main limitations of the study is that, due to its cross-sectional design, it cannot support causal relationships between perinatal or sociodemographic or lifestyle correlates and body composition indices. Moreover, the retrospective collection of data via the parental recall could be considered a methodological bias that should be kept in mind when interpreting the findings of the present study. Lastly, although some variables included in the multivariate regression analysis model could act as confounders in certain associations between the independent and dependent variables, some other variables could act as mediators. Nevertheless, the multivariate regression analyses performed in the present study to identify potential independent associations of perinatal, sociodemographic and lifestyle factors with increased fat mass levels in children cannot discern potential confounders from mediators and this could be accounted as another limitation of the present work.

Overall, the results of the present study showed that smoking during pregnancy, the rate of child development during the first months of life, parental BMI, father's age, maternal educational level, daily energy expenditure due to exercise and sedentary behaviours such as daily hours spent on TV are associated with children's higher levels of total and visceral fat mass. The present study is the first to examine possible independent associations of a large number of perinatal, socio-economic factors and lifestyle characteristics of children and families in relation to children's total and visceral fat mass. These results highlight the importance of intervention programmes beginning early in life because of the strength of the associations between preconception factors and fat mass levels in childhood. In this regard, future intervention programmes starting from early life stages need to be designed and implemented in order to pave the way for new, more effective and sustainable approaches for tackling the childhood obesity epidemic and its cardiometabolic complications in adult life.

\section{Acknowledgements}

Acknowledgements: The authors would like to thank the Healthy Growth Study Group for the valuable contribution to the completion of the study. Financial support: This research was co-financed by the European Union (European Social Fund; ESF) and Greek national funds through the Operational Programme 'Education and Lifelong Learning' of the National Strategic Reference Framework (NSRF) - Research
Funding Programme: 'Heracleitus II. Investing in knowledge society through the European Social Fund'. The funders had no role in the design, analysis or writing of this article. Conflicts of interest: None. Authorship: G.M., study design, data collection, data analysis, data interpretation. A.C.K., data analysis, data interpretation. K.K., data analysis, data interpretation. M.A., data collection, literature review. C.-P.L., data collection, literature review. A.K.K., data collection, literature review. G.P.C., study design, data interpretation. C.L., study design, data interpretation. Y.M., study design, data interpretation. All authors contributed in drafting the manuscript, reviewed and approved the final version. Ethics of human subject participation: This study was conducted according to the guidelines laid down in the declaration of Helsinki and all procedures involving human subjects were approved by the Greek Ministry of National Education and the Ethics Committee of the Harokopio University of Athens. Written informed consent was obtained from all subjects. The Healthy Growth Study Group: Harokopio University Research Team/Department of Nutrition and Dietetics: Yannis Manios (Coordinator), George Moschonis (Project Manager), Katerina P. Skenderi, Evangelia Grammatikaki, Odysseas Androutsos, Sofia Tanagra, Alexandra Koumpitski, Paraskevi-Eirini Siatitsa, Anastasia Vandorou, Aikaterini-Efstathia Kyriakou, Vasiliki Dede, Maria Kantilafti, Aliki-Eleni Farmaki, Aikaterini Siopi, Sofia Micheli, Louiza Damianidi, Panagiota Margiola, Despoina Gakni, Vasiliki Iatridi, Christina Mavrogianni, Kelaidi Michailidou, Aggeliki Giannopoulou, Efstathoula Argyri, Konstantina Maragkopoulou, Maria Spyridonos, Eirini Tsikalaki, Panagiotis Kliasios, Anthi Naoumi, Konstantinos Koutsikas, Epistimi Aggelou, Zoi Krommyda, Charitini Aga, Manolis Birbilis, Ioanna Kosteria, Amalia Zlatintsi, Elpida Voutsadaki, Eleni-Zouboulia Papadopoulou, Zoi Papazi, Maria Papadogiorgakaki, Fanouria Chlouveraki, Maria Lyberi, Nora Karatsikaki-Vlami, Eva Dionysopoulou and Efstratia Daskalou.

\section{References}

1. Brug J, van Stralen MM, Chinapaw MJ et al. (2012) Differences in weight status and energy-balance related behaviours according to ethnic background among adolescents in seven countries in Europe: the ENERGYproject. Pediatr Obes 7, 399-411.

2. Brug J, van Stralen MM, Te Velde SJ et al. (2012) Differences in weight status and energy-balance related behaviors among schoolchildren across Europe: the ENERGY-project. PLoS One 7, e34742.

3. Lobstein T \& Frelut ML (2003) Prevalence of overweight among children in Europe. Obes Rev 4, 195-200.

4. Moschonis G, Kalliora AC, Costarelli V et al. (2014) Identification of lifestyle patterns associated with obesity and fat mass in children: the Healthy Growth Study. Public Health Nutr 17, 614-624.

5. Abrams P \& Levitt Katz LE (2011) Metabolic effects of obesity causing disease in childhood. Curr Opin Endocrinol Diabetes Obes 18, 23-27.

6. Daniels SR, Arnett DK, Eckel RH et al. (2005) Overweight in children and adolescents: pathophysiology, consequences, prevention, and treatment. Circulation 111, 1999-2012. 
7. Birbilis M, Moschonis G, Mougios V et al. (2013) Obesity in adolescence is associated with perinatal risk factors, parental BMI and sociodemographic characteristics. Eur J Clin Nutr 67, 115-121.

8. Javed A, Jumean M, Murad MH et al. (2014) Diagnostic performance of body mass index to identify obesity as defined by body adiposity in children and adolescents: a systematic review and meta-analysis. Pediatr Obes 10, 234-244.

9. Moschonis G, Tanagra S, Vandorou A et al. (2010) Social, economic and demographic correlates of overweight and obesity in primary-school children: preliminary data from the Healthy Growth Study. Public Health Nutr 13, 1693-1700.

10. International Obesity Task Force (2005) Global prevalence of obesity. http://www.worldobesity.org/resources/childobesity/ (accessed January 2016).

11. Ryo M, Maeda K, Onda T et al. (2005) A new simple method for the measurement of visceral fat accumulation by bioelectrical impedance. Diabetes Care 28, 451-453.

12. Nielsen BM, Dencker M, Ward L et al. (2007) Prediction of fat-free body mass from bioelectrical impedance among 9- to 11-year-old Swedish children. Diabetes Obes Metab 9 , 521-539.

13. Institute of Medicine (2009) Weight gain during pregnancy: reexamining the guidelines. http://www.nationalacademies. org/hmd/ /media/Files/Report\%20Files/2009/Weight-GainDuring-Pregnancy-Reexamining-the-Guidelines/Report $\%$ 20Brief\%20-\%20Weight\%20Gain\%20During\%20Pregnancy.pdf (accessed January 2016).

14. Trichopoulou A (2004) Composition Tables of Foods and Greek Dishes. Athens: Department of Hygiene and Epidemiology, University of Athens School of Medicine.

15. O'Neil CE, Byrd-Bredbenner C, Hayes D et al. (2014) The role of breakfast in health: definition and criteria for a quality breakfast. J Acad Nutr Diet 114, 12 Suppl., S8-S26.

16. Farajian P, Risvas G, Karasouli K et al. (2011) Very high childhood obesity prevalence and low adherence rates to the Mediterranean diet in Greek children: the GRECO study. Atherosclerosis 217, 525-530.

17. Franca-Neto AH, Amorim MM, de Oliveira Barros V et al. (2014) Is newborn abdominal adiposity associated with maternal factors? Obstet Gynecol 123, Suppl. 1, 51S-52S.

18. Catalano PM \& Ehrenberg HM (2006) The short- and long-term implications of maternal obesity on the mother and her offspring. BJOG 113, 1126-1133.

19. Radaelli T, Lepercq J, Varastehpour A et al. (2009) Differential regulation of genes for fetoplacental lipid pathways in pregnancy with gestational and type 1 diabetes mellitus. Am J Obstet Gynecol 201, 209.e1-209.e10.

20. Catalano PM, Farrell K, Thomas A et al. (2009) Perinatal risk factors for childhood obesity and metabolic dysregulation. Am J Clin Nutr 90, 1303-1313.

21. Stettler N, Kumanyika SK, Katz SH et al. (2003) Rapid weight gain during infancy and obesity in young adulthood in a cohort of African Americans. Am J Clin Nutr 77, 1374-1378.

22. Stettler N, Zemel BS, Kumanyika S et al. (2002) Infant weight gain and childhood overweight status in a multicenter, cohort study. Pediatrics 109, 194-199.

23. Ong KK, Emmett P, Northstone K et al. (2009) Infancy weight gain predicts childhood body fat and age at menarche in girls. J Clin Endocrinol Metab 94, 1527-1532.

24. Demerath EW, Reed D, Choh AC et al. (2009) Rapid postnatal weight gain and visceral adiposity in adulthood: the Fels Longitudinal Study. Obesity (Silver Spring) 17, 2060-2066.

25. Singhal A (2010) Does weight gain in infancy influence the later risk of obesity? J Pediatr Gastroenterol Nutr 51, Suppl. 3, S119-S120.

26. Monteiro PO \& Victora CG (2005) Rapid growth in infancy and childhood and obesity in later life - a systematic review. Obes Rev 6, 143-154.
27. Baird J, Fisher D, Lucas P et al. (2005) Being big or growing fast: systematic review of size and growth in infancy and later obesity. BMJ 331, 929.

28. Ong KK \& Loos RJ (2006) Rapid infancy weight gain and subsequent obesity: systematic reviews and hopeful suggestions. Acta Paediatr 95, 904-908.

29. Singhal A \& Lucas A (2004) Early origins of cardiovascular disease: is there a unifying hypothesis? Lancet 363, 1642-1645.

30. Oken E, Levitan EB \& Gillman MW (2008) Maternal smoking during pregnancy and child overweight: systematic review and meta-analysis. Int J Obes (Lond) 32, 201-210.

31. Raum E, Kupper-Nybelen J, Lamerz A et al. (2011) Tobacco smoke exposure before, during, and after pregnancy and risk of overweight at age 6. Obesity (Silver Spring) 19, 2411-2417.

32. Suzuki K, Ando D, Sato M et al. (2009) The association between maternal smoking during pregnancy and childhood obesity persists to the age of 9-10 years. J Epidemiol 19, 136-142.

33. Durmus B, Kruithof CJ, Gillman MH et al. (2011) Parental smoking during pregnancy, early growth, and risk of obesity in preschool children: the Generation R Study. Am J Clin Nutr 94, 164-171.

34. Koshy G, Delpisheh A \& Brabin BJ (2011) Dose response association of pregnancy cigarette smoke exposure, childhood stature, overweight and obesity. Eur J Public Health 21, 286-291.

35. Leary SD, Smith GD, Rogers IS et al. (2006) Smoking during pregnancy and offspring fat and lean mass in childhood. Obesity (Silver Spring) 14, 2284-2293.

36. Ay L, Hokken-Koelega AC, Mook-Kanamori DO et al. (2008) Tracking and determinants of subcutaneous fat mass in early childhood: the Generation $\mathrm{R}$ Study. Int $J$ Obes (Lond) 32, 1050-1059.

37. Oken E, Huh SY, Taveras EM et al. (2005) Associations of maternal prenatal smoking with child adiposity and blood pressure. Obes Res 13, 2021-2028.

38. Von Schnurbein J, Klenk J, Galm C et al. (2011) Reference values and early determinants of intra-abdominal fat mass in primary school children. Horm Res Paediatr 75, 412-422.

39. Syme C, Abrahamowicz M, Mahboubi A et al. (2010) Prenatal exposure to maternal cigarette smoking and accumulation of intra-abdominal fat during adolescence. Obesity (Silver Spring) 18, 1021-1025.

40. Timmermans SH, Mommers M, Gubbels JS et al. (2010) Maternal smoking during pregnancy and childhood overweight and fat distribution: the KOALA Birth Cohort Study. Pediatr Obes 9, e14-e25.

41. Wilding JP (2002) Neuropeptides and appetite control. Diabet Med 19, 619-627.

42. Wideroe M, Vik T, Jacobsen G et al. (2003) Does maternal smoking during pregnancy cause childhood overweight? Paediatr Perinat Epidemiol 17, 171-179.

43. Cooper R, Hypponen E, Berry D et al. (2010) Associations between parental and offspring adiposity up to midlife: the contribution of adult lifestyle factors in the 1958 British Birth Cohort Study. Am J Clin Nutr 92, 946-953.

44. Staiano AE, Harrington DM, Broyles ST et al. (2013) Television, adiposity, and cardiometabolic risk in children and adolescents. Am J Prev Med 44, 40-47.

45. Saelens BE, Seeley RJ, van Schaick K et al. (2007) Visceral abdominal fat is correlated with whole-body fat and physical activity among 8-y-old children at risk of obesity. Am J Clin Nutr 85, 46-53.

46. Batada A, Seitz MD, Wootan MG et al. (2008) Nine out of 10 food advertisements shown during Saturday morning children's television programming are for foods high in fat, sodium, or added sugars, or low in nutrients. J Am Diet Assoc 108, 673-678.

47. Huang L, Mehta K \& Wong ML (2012) Television food advertising in Singapore: the nature and extent of children's exposure. Health Promot Int 27, 187-196. 